\title{
Management Plan Optimization and Application of Public Spots for Increasing Widespread Usage of Public Transportation: Istanbul Case
}

\author{
Ummugulsum Alyuz, H. Handan Demir, H. Eser Okten, Oktay Yilmaz, and Goksel Demir
}

\begin{abstract}
Increasing the widespread usage of the public transportation has a vital importance for reducing environmental pollution originated from the transport sector which is one of the biggest causes of the global warming. In this study, first of all the factors affecting a management plan on increasing the public interest in public transport were investigated, then Istanbul case was explained for each of these factors, the success of the applications were discussed and suggestions were provided for improvement through the application of the short informative audiovisual advertisements. Finally, a management plan was optimized for the usage of public transportation dissemination, which can be adapted by decision-makers in accordance with the internal dynamics of their own countries and recommendations were included to increase demand by usage of public spots.
\end{abstract}

Index Terms-Public transport, public spot, audiovisual advertisement, management plan.

\section{INTRODUCTION}

As the population residing in cities and the gross domestic product increase the overall welfare of people also increases, correlating with the increased use of individually owned vehicles instead of public transportation. Also the demand on petroleum increases since it is the primary fuel that is used for combustion in vehicle engines. Extensive consumption of fossil fuels and inefficient combustion of petroleum, along with the traffic congestions in cities like Istanbul result in air pollution and noise pollution, which have negative temporal and spatial effects on human and environmental health. In Turkey, 88.5\% of CO2 emissions are originated from road transport alone, and $41.4 \%$ of this amount comes from private cars in 2010 [1]. Since Turkey is not petroleum producing country, with the increasing petroleum demand more financial resources are needed to be allocated for supply. Furthermore in order to find solution to traffic related problems more of the local administration budget should be directed to optimization studies. While considering solutions to traffic related problems, public transportation should be evaluated as a viable option and influential measures such as

Manuscript received October 20, 2012; revised February 7 , 2013.

U. Alyuz, H. E. Okten, and G. Demir are with the Bahcesehir University Environmental Engineering Department, Besiktas Istanbul, Turkey (e-mail: ummugulsum.alyuz@bahcesehir.edu.tr, eser.okten@bahcesehir.edu.tr, goksel.demir@bahcesehir.edu.tr)

H. H. Demir is with the Bahcesehir University Vocational School Department of Business Administration, Besiktas Istanbul, Turkey (e-mail: hacerhandan.demir@bahcesehir.edu.tr)

O. Yilmaz is with the Istanbul Metropolitan Municipality, Istanbul, Turkey (e-mail: goksel.demir@ bahcesehir.edu.tr) broadcasting short informative advertisements through audiovisual media should be taken. This can be also evaluated in the context of awareness building and it will most probably influence people's choices in the favor of public transportation.

In this study Istanbul was chosen to be the studied case with its unique characteristics including a strait that not only divides the city in half but also defines the border of two continents. Although Istanbul comprises 1\% of Turkey in terms of area, $18.23 \%$ of Turkey's population lives in Istanbul [2]. The $10 \%$ of the daily commute done by Istanbul residents include inter-continental passages [3]. Marine transportation takes up about $3.3 \%$ of the total transportation, while rail system accounts for $13.2 \%$ and the remaining $83.5 \%$ of the total transportation is done by motor vehicles. By the year 2011 the total commuter number in a day has reached 10.341.170 people [4]. However the optimization of public transportation system for Istanbul still remains a challenge, lacking harmonization and transit between different means of public transportation. Furthermore current public transportation system cannot meet the high demand in Istanbul in terms of quality and quantity. Moreover the long distances between residential areas and workplaces also contribute to choice of driving instead of riding.

\section{METHOD}

In the preliminary study, factors that affect the preference of driving over riding are determined by investigating the current status in Turkey and in other big cities in the world and by listing the important factors that influence commuter choices. Then these factors were categorized in two groups, more specifically as factors that can be effective in the decision-making process and factors that were considered in increasing the popularity of current public transportation practices. Important factors were evaluated through examples on the city of Istanbul and propositions were made. In conclusion, the use short informative advertisements through audiovisual media for building awareness and increasing popularity of public transportation were proposed and the application methodology was presented.

\section{OPtIMIZATION OF APPLICABLE METHODS FOR} INCREASING PUBLIC TRANSPORTATION USE AND THE CASE OF ISTANBUL

In order to increase the use of public transportation methods that can be applied to future projects and current 
public transportation system is summarized in Fig. 1. For each and every one of these methods the case of Istanbul is studied and measures that can be taken in order to conduct optimization of the methods at similar regions are briefly presented.

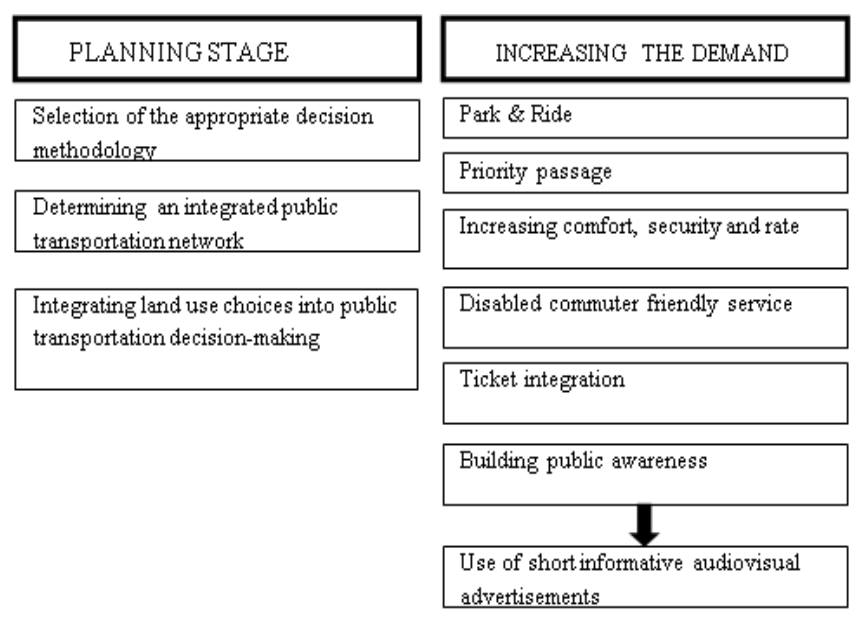

Fig. 1. Applied methods to increase use of public transportation in planning or in the application period.

Transportation lines and modes are vital for a city’s economic and social life. Also investments in transportation are in capital and operational costs. Therefore a comprehensive evaluation should be conducted prior to every investment. [5] The mostly frequently used methods for deciding the mode of transportation are the Cost-Benefit Analysis and the Multivariate Analysis. In cost-benefit analysis benefits are depicted as the profit gained from the transportation mode and costs are the total expenditure. The entire evaluation in cost-benefit analysis proceeds on the basis of monetary value and externalities are not considered. On the other hand in multivariate analysis, system constituents that cannot be represented in terms of money easily such as time savings, are included. Multivariate analysis requires expert view extensively and however subjective that is, this method is more reliable. Therefore facilitating the multivariate analysis at the decision-making stage for the transportation investment is suggested.

Planning of transportation modes to work in harmony with each other, keeping walking distances at the transfer stations relatively short, making stations and vehicles accessible to everyone, easily understood and sufficient number of signs, serving the departure and arrival points within the public transportation system are important factors affecting the preference of public transportation following decision-making and investment stages. When Istanbul is studied for integration of public transportation modes with each other, the Asian side of the city has a much better report card than the European side, mostly due to lack of easy passage between the main bus line and the nearest subway station. Solution to the problem comes by the underground connection of bus station to the subway station through escalators.

Rate of urbanization, possible land use options and their integration with the public transportation systems should be considered at the stage of deciding the public transportation lines. Accordingly, projections for future urbanization should be conducted in order to allow easy integration and flexible service providing. Simultaneously in cities like Istanbul, which is mostly urbanized in an unplanned manner, urban transformation projects are real and viable and therefore public transportation systems should be planned to facilitate these transformations. At regions that are picked to be transformation foci, public transportation projects that are integrated to the nearest main system should be prepared ahead of time. In such projects decision-makers can be from different local administrations resulting in conflicting situations. Planning prior to transformation projects is vital in that perspective so that any conflict between decision-makers can be resolved in time, and all stakeholders in the process can contribute.

[5] Along with optimization studies that target increasing preference in the favor of public transportation, various facilities can be conducted in order to raise awareness regarding the current system. Advertisement campaigns are effective ways of communicating with large numbers of people. Also it is known that good practices, saving time and money on public transportation on a daily basis, speak for themselves.

In order to facilitate choosing public transportation over driving and therefore reducing pollutant emissions, noise pollution, traffic congestions and time spent in traffic, the Park and Ride system is in effect in Istanbul and in most of the big cities in the world. In this system drivers are provided with reduced rates for parking at different parts of the city with the aim of directing drivers to use public transportation. Also there may be deals offering further reduced rates of parking fees and tickets indirectly proportional to increased passengers in a vehicle. As a result traffic in the city will be lighter and the drivers will reach their destination spending less money and time. For Istanbul public transportation projects are expected to take $100 \mathrm{~km}$ out of traffic by a public transportation fleet of 10,000 vehicles. This major project also predicts to reduce the carbon dioxide emissions by 700 tons per year and benefit economy 15 million TL annually.

In the cases where the distance to and between stops does not deem walking feasible then cycling comes up as an option. In the relatively flat regions (slope $<5 \%$ ) building bicycle paths and bicycle parking lots, and providing bicycle rental services increase integration of cycling into the public transportation system. At the same time different modes of public transportation vehicles may be designed to work with bicycles such as implementation of bicycle racks in front of buses. Unfortunately integrating use of bicycle in a city like Istanbul, where the traffic jams are everyday issues, some streets do not have even pavements, and the slopes are generally steeper than $10 \%$, is a challenge and a requirement. Municipalities try to encourage cycling at least at recreational areas and at the coastline but it is still very limited. For cycling in Istanbul to get to be a widespread practice drivers should be educated, and cultural prejudices should be overcome. Until then smaller regions can be selected as pilot regions for trial and gaining experience before application in full-scale.

A questionnaire study is conducted by the municipality owned local bus company (IETT) interviewing 1121 people [4]. The study showed that 8 people out of 10 preferred the 
main bus line running between the continents for its speed, comfort and traffic-free private route. The main complaint regarding the main bus line rides is the over-crowdedness. The riders of the inter-continental main bus line think that it is fast and reliable to use that particular mode of public transportation and that also the bus stops are clean and safe. The $10 \%$ of interviewed people stated that prior to using the main bus line they used to use relatively comfortable lines but they converted to using the inter-continental main bus line when it became active in 2009, nevertheless. $5 \%$ of the interviewed people stated that they used to drive or hire a cab for the same route before the main bus line was put into service.

Rule of transition is applied for public transport in any circumstances in London where the part of public transportation in the city is provided by private companies, has a population of approximately half of Istanbul, but the amount of daily passenger transportation is 2 times of Istanbul [6]. Unfortunately it does not seem possible in Istanbul which has current and increasing traffic problem, however a pilot application related with separation of the public transport lane was started in 2012.

Electronic card (electronic ticket) allows passengers to transport by 5 different transport vehicle for 120 minutes after the first ride and applied in Istanbul very well in terms of ticket integration. However taxis and minibuses are not charged whether they are integrated in public transport, therefore the system should be improved by adding them by considering their transporting responsibilities.

187500 physically disabled, 90.000 visually impaired citizens who are the $12.9 \%$ of the overall population should not be evaluated for increasing widespread usage of public transportation, but considered for social integration. Audio-visual information about issues, lines, and vehicle times will increase the reputation of passengers to the system passengers will save time and will make public vehicles attractive. In Istanbul, the system is under development.

\section{ApPliCATION OF INFORMATIVE AdVERTISEMENTS}

Informative advertisements are prepared in order to raise awareness in public and are paid by central or local administrations. These advertisements aim to engage public in good practices effecting health, economy and environment. For example quitting smoking, abiding by traffic laws, donating organs can be listed among the successful awareness-raising applications of short informative audiovisual advertisement campaigns. In this context, the Smoke-Free Air Zone campaign, banning smoking in public areas was a huge success in Turkey. Furthermore, World Health Organization (WHO) praised Turkey for the best application example in the fight with smoking along with Hungary, United Kingdom and Sweden. In 2008 smokers were $31 \%$ of the population and this value receded back to $27 \%$ by the year 2010. Therefore experience on informative advertisement applications gained by the Ministry of Health can be conveyed to Ministry of Transportation through inter-institutional communication. The benefits of public transportation can be effectively transferred to the main public by highlighting some points with benefit details as indicated in Table I.

TABLE I: BENEFITS THAT ARE EMPHASIZED IN INFORMATIVE ADVERTISEMENT APPLICATIONS.

\begin{tabular}{|c|c|}
\hline Emphasized Point & Benefit Details \\
\hline $\begin{array}{l}\text { Contribution to } \\
\text { Individual's Budget }\end{array}$ & Emphasis on savings from fuel costs \\
\hline $\begin{array}{l}\text { Contribution to Country’s } \\
\text { Economy }\end{array}$ & $\begin{array}{l}\text { Emphasis on decreasing dependency on } \\
\text { other countries }\end{array}$ \\
\hline Fast Transportation & $\begin{array}{l}\text { Proving that using public transportation is } \\
\text { faster }\end{array}$ \\
\hline Healthy Generations & $\begin{array}{l}\text { Daily exercises can be done by walking } \\
\text { while using public transportation modes }\end{array}$ \\
\hline Healthy Environment & Reduction in air and noise pollution \\
\hline Comfort in Transportation & $\begin{array}{l}\text { Instead of driving, other activities such as } \\
\text { reading can be done to make use of } \\
\text { transportation time. }\end{array}$ \\
\hline
\end{tabular}

Countries without oil resources such as Turkey, the fuel need of the vehicles for the movement is supplied by purchasing crude petroleum from abroad, and it makes the country dependent to the abroad. Also public transportation provides significant fuel savings, therefore has a positive effect to the country and individual economics. Additionally the air and noise pollution increase with the usage of private cars, and the effects of this pollution to the human health such as neurologic and physical problems should be highlighted. In Istanbul, the average distance is about 10-12 minutes for access to public transport stops and it is adequate for daily sport need (30 minutes-1 hour walking) for a person who uses different vehicles per day. These points should be emphasized in public spots to make positive impact on society in terms of increasing public awareness to the public transport.

In the application phase all the decision-makers should be aware of all system inputs, constituents and outputs so that public can be informed thoroughly. Also academia should participate in the informing process via conducting studies and publishing on urban transportation systems. An exemplary practice is public transportation use by popular and pertinent figures of the public. The chosen popular role-models may take part in the informative advertisement campaigns conveying the message effectively to the public. The environmental aspect of public transportation should be emphasized to raise awareness among the young generation. Using public transportation for more than 4 individual rides in a day may not be realistic; however, for 1-2 individual rides it is feasible in Istanbul.

\section{CONCLUSION}

The process of public participation in transportation should be evaluated as a whole considering public awareness, disabled citizens, urban transformation projects, along with monetary terms, comfort, speed, etc. Planning modes and lines for public transportation for future projects are rather easy when compared with planning remediation on current public transportation systems. The most important point that requires immediate attention is providing the smooth integration of different modes of public transportation. Eventually the improvement efforts require investment in 
large sums but it should be noted that in the long run these investments will benefit the economy by reducing fossil fuel dependency and carbon budgets.

The continuity of investments on public transportations is crucial in order to keep the system up-to-date and safe. Also the administrations should abide with the master plan of public transformation and subjective changes should be avoided. Local administration views tend to change as the political power change sides and at this point it is important for local administrations to consult with academia and non-governmental organizations. In conclusion, preferring public transportation over driving is a function of social, economic and cultural codes and it should proceed on the voluntary basis rather than enforcements.

\section{REFERENCES}

[1] Turkish Statistical Institute, National Greenhouse Gas Inventory Report 1990-2010, 2012.

[2] Turkish Statistical Institute Statistics. (2012). [Online]. Available: http://www.tuik.gov.tr

[3] IUAP Project Team (2011). Istanbul Metropolitan Area Urban Transportation Plan for year 2006.

[4] Personal Communication (2011), Istanbul Metropolitan Municipality, Transportation Department.

[5] O. Yilmaz, "A study on public transportation and possible efforts on wide spread usage: Istanbul Case," Master Dissertation. Bahcesehir University Urban Systems and Transportation Assessment Master Program, 2012.

[6] M. Yazici, "Total Quality Management in Urban Public Transportation Services and an Application,” Master's Thesis, Marmara University SBE, 2010.

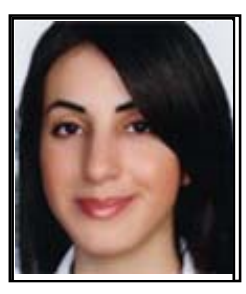

Ummugulsum Alyuz was born in Malatya, Turkey in 1984. She has MSc. degree in Environmental Engineering, Istanbul Technical University in 2012 and other master degree as MBA in Istanbul University in 2010 and B.S. degree in Environmental Engineering Trakya University (2008). Currently she is a $\mathrm{PhD}$ candidate of Istanbul Technical University. Her research interests are Air Pollution and Control, Solid Waste Management. She is assigned as a Research Assistant in Bahcesehir University, Istanbul Turkey, Department of Environmental Engineering in 2012 and worked as an engineer in Cevka Construction Co Ltd from 2008 to 2012 in the solid waste management sector.

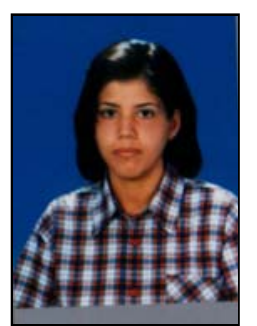

Hacer H. Demir was born in Istanbul Turkey in, 1978. She has MSc. degree in Production Management Department of Istanbul University and continues her PhD in the same department. She has also BSc degree in Chemical Engineering Department of Istanbul University in 2000. She is working as a teaching member in Bahcesehir University Vocational School, Department of Business Administration in Istanbul Turkey.

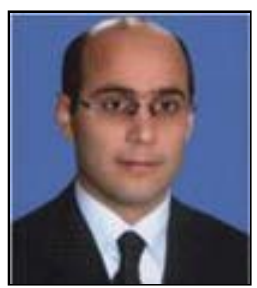

Goksel Demir was born in Agri, Turkey in 1970 He has Ph.D. degree in environmental engineering, Istanbul University in 2002. He has M.S. degree in Environmental engineering (1997) and B.S. degree in Biology in Istanbul University (1993). His research interests are Air Pollution and Control, Microbial Fuel cells and Sustainable Power Generation, Water Pollution and Control. He was assigned as a Research Assistant in Istanbul University, Department of Environmental Engineering in 1994, and Dr. Research Assistant in 2002 and Assistant Professor in 2004, Assistant Professor in Bahcesehir University Department of Environmental Engineering in 2006. Currently he is working as Associated Professor in Bahcesehir University Department of Environmental Engineering in Istanbul, Turkey since 2008.

Dr. Demir is Adviser Board Member of "Journal of Laboratory World" and member of Mediterranean Scientific Association of Environmental Protection (MESAEP), International Solid Waste Association (ISWA) and American Association for the Advancement of Science (AAAS)

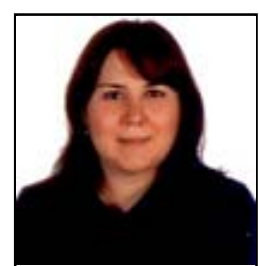

Hatice E. Okten was born in Istanbul, Turkey in 1980. She has Ph.D. degree in environmental engineering, University of Wisconsin-Madison in 2008. She has M.S. degree in Environmental Engineering (2002) and B.S. degree in Environmental Engineering in Istanbul University (1999). Her research interests are water and wastewater treatment. She has assigned as Assistant Professor in Bahcesehir University, in Istanbul Turkey since 2008 and as Research Assistant in Istanbul Technical University between 2000 and 2002.

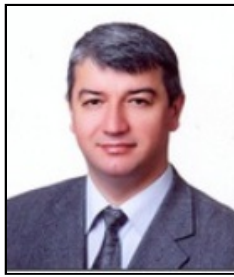

Oktay Yilmaz was born in Rize, Turkey in 1972. He has BSc degree in Istanbul Technical University Urban and Regional Planning Department in 1995 and MSc. degree in Urban Systems and Transportation Assessment Master Program of Bahcesehir University in 2012. He has working in Istanbul Metropolitan Municipality since 2005. 